\title{
Polyphenols Extracted from Olive Mill Wastewater Exert a Strong Antioxidant Effect in Human Neutrophils
}

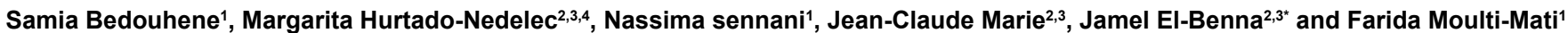

${ }^{1}$ Laboratoire de Biochimie appliquée et de biotechnologie, Faculté des Sciences Biologiques et des Sciences Agronomiques, Université M. Mammeri, BPN¹7, RP 15000 Tizi-Ouzou, Algeria

2Inserm, U1149, CNRS-ERL8252, Centre de Recherche sur I'Inflammation, Paris, France

${ }^{3}$ Université Paris Diderot, Sorbonne Paris Cité, Laboratoire d'Excellence Inflamex, Faculté de Médecine, Site Xavier Bichat, Paris, France

${ }^{4}$ AP-HP, Unité Dysfonctionnement Immunitaire, Centre Hospitalo-Universitaire Xavier Bichat, Paris, F-75018, France

\begin{abstract}
Olive mill wastewater (OMW) is produced seasonally by the olive oil-producing countries. A large amount of liquid waste results from olive oil extraction, with a very high organic load which renders it difficult to treat. Wastewater represents also a significant source of polyphenols which can be revalorized and used for medical or agro-alimentary purposes. The extraction of polyphenols will improve the wastewater biodegradation and reduce its phytotoxicity. The objective of this study was to extract polyphenols from OMW and to investigate their effect on reactive oxygen species (ROS) production by human neutrophil. Polyphenols were extracted from OMW by an established technique. Neutrophils, isolated from blood of healthy volunteers, were incubated with increased concentrations of polyphenol extract and ROS production was measured by luminol-amplified chemiluminescence and cytochrome $c$ reduction techniques. Results show that the polyphenol extract from OMW inhibited phorbolmyristate acetate (PMA)-stimulated neutrophil ROS production as measured by the chemiluminescence assay. The polyphenols extract from OMW also inhibited neutrophil superoxide production as measured by the cytochrome $\mathrm{C}$ reduction assay; as well as $\mathrm{H}_{2} \mathrm{O}_{2}$ production as measured by flow cytometry. Also, the polyphenol extract reacted with pure $\mathrm{H}_{2} \mathrm{O}_{2}$ but did not affect superoxide anions production by the xanthine/xanthine oxidase enzymatic system. Our results show that polyphenols extracted from OMW exert a strong antioxidant effect and they could have an anti-inflammatory effect by inhibiting neutrophil ROS production and by scavenging hydrogen peroxide, thus limiting their toxic effects. OMW could be used to extract polyphenols for medicinal applications.
\end{abstract}

Keywords: Antioxidant; Olive mill wastewater; Polyphenols; Polymorphonuclear neutrophils; Reactive oxygen species

\section{Introduction}

The Mediterranean region is the first producer of olive oil in the world. Despite the known beneficial properties of olive oil on health, its production generates large amounts of by-products such as olive mill wastewater (OMW) [1], which constitutes an important environmental pollution product. The Mediterranean region accounts for $95 \%$ of the global OMW product in the world [2]. Phenolic compounds such as oleuropein, tyrosol, hydroxytyrosol and caffeic acid are abundant in OMW [3,4]. The presence of polyphenols in olive oil is believed to be responsible for its stability [5]. Olive polyphenols are also known to play a role in preventing chronic human diseases such as cardiovascular diseases and inflammatory diseases [6]. Several in vitro and in vivo studies confirmed that phenolic compounds from olive reduce the effect of oxidative stress associated with pathological disorders including atherosclerosis $[7,8]$, cancer $[9,10]$, inflammatory diseases [11-13], neurodegenerative diseases [14], and they have some anti-microbial and anti-viral properties [15-18].

Reactive oxygen species (ROS) such as superoxide anion $\left(\mathrm{O}_{2}^{*-}\right)$, hydrogen peroxide $\left(\mathrm{H}_{2} \mathrm{O}_{2}\right)$ and hydroxyl radical $\left(\mathrm{OH}^{*}\right)$ are powerful oxidants produced by several enzymatic systems in the body [19]. Phagocytes such as neutrophils, monocytes and macrophages are major ROS producing cells [20]. Neutrophil activation leads to the production of ROS in a process called respiratory burst, mediated by a multi-component enzyme NADPH oxidase. ROS produced by this process are used by phagocytes to kill infectious agents. In contrast, over production of ROS may cause oxidative stress, leading to many deleterious effects for the organism [21]. In this context, polyphenol compounds, known to have an antioxidant effect, can be used to protect cell against oxidative damage and limit the risk of various degenerative diseases associated to excessive ROS production by phagocytes. While, individual polyphenol compounds have been shown to display antioxidative effect, little is known about the effect of total polyphenol extracts from OMW [22-25]. In this work, we used OMW, from chemlal variety olive tree which is largely cultivated in Kabylia (Algeria), to extract polyphenols. Polyphenol extract were tested on ROS production by human neutrophils and enzymatic systems.

\section{Materials and Methods}

\section{Materials}

Ficoll, Dextran, cytochrome C, luminol, PMA (4b-phorbol-12bmyristate-a13-acetate), xanthine, xanthine-oxidase, $\mathrm{H}_{2} \mathrm{O}_{2}, \mathrm{HRPO}$ (horseradish peroxidase), 2',7' - Dichlorofluorescin diacetate (DCFHDA), Dulbecco's Phosphate-buffered saline (PBS) and Hanks' balanced salt solution (HBSS) were purchased from Sigma- Aldrich Chemie $\mathrm{GmbH}$ (Steinheim, Germany). The different solutions were diluted in phosphate-buffered saline (PBS) immediately before use.

\section{Extraction of polyphenols from olive mill wastewater}

Polyphenols were extracted according to the method previously

*Corresponding author: Dr Jamel El Benna, Faculté de Médecine Xavier Bichat, 16 rue Henri Huchard, Paris, F-75018, France, Tel.: +33-157277723; Fax: +33157277471; E-mail: jamel.elbenna@inserm.fr

Received September 13, 2014; Accepted October 16, 2014; Published October 20,2014

Citation: Bedouhene S, Hurtado-Nedelec M, Sennani N, Marie JC, El-Benna J et al. (2014) Polyphenols Extracted from Olive Mill Wastewater Exert a Strong Antioxidant Effect in Human Neutrophils. Int J Waste Resources 4: 161. doi: 10.4172/2252-5211.1000161

Copyright: (c) 2014 Bedouhene S, et al. This is an open-access article distributed under the terms of the Creative Commons Attribution License, which permits unrestricted use, distribution, and reproduction in any medium, provided the original author and source are credited. 
described [4]. Olive mill wastewater was collected from the region of Kabylia, the most important producer of olive oil in Algeria (Algeria). Liquid-liquid extraction of phenolic compounds with ethyl acetate was carried out on olive mill wastewater samples obtained from a continuous olive oil processing plant. OMW was acidified to $\mathrm{pH} 2$ with $\mathrm{HCl}$ and washed with hexane in order to remove the lipid fraction, the mixture was vigorously shaken and centrifuged for $5 \mathrm{~min}$ at $3000 \mathrm{rpm}$. The phases were separated and washed successively twice. Extraction of phenolic compounds was then carried out with ethyl acetate: the washed OMW samples were mixed with ethyl acetate and vigorously shaken before centrifugation for $5 \mathrm{~min}$ at $3000 \mathrm{rpm}$. The phases were separated and the extraction was repeated four times successively. The ethyl acetate was evaporated using a speed Vac. The aliquots of polyphenol extract without solvent were frozen $\left(-20^{\circ} \mathrm{C}\right)$ until utilization.

\section{Determination of total polyphenol content}

Total polyphenol compounds in OMW extract was determined by the Folin-Ciocalteu assay according to the method described by Singleton [26]. The absorbance was read at $725 \mathrm{~nm}$ in Uvikon 931 (Contron, Milano, Italy) UV-Vis spectrophotometer and all the experiments were performed in triplicate. The content of total polyphenol is reported as gallic acid equivalents (EqGA) by reference to standard curve. For experiments, polyphenols extract was prepared at $5 \mathrm{mg} / \mathrm{mL}$ in PBS then diluted in the assay at different concentrations.

\section{Neutrophil preparation}

Neutrophils were isolated from venous heparinized blood, freshly collected from healthy volunteers. We used Dextran (T500) to remove red blood cells, followed by centrifugation over Ficoll-Paque to remove mononuclear cells and hypotonic lysis of any remaining contaminating red blood cells as described previously [2]. Finally, the neutrophils were centrifuged and suspended in PBS before being counted.

\section{Determination of cell viability}

Isolated human neutrophils were incubated with polyphenols extract at concentrations of $0,25,50,100,200$ and $250 \mu \mathrm{g} / \mathrm{mL}$ during $30 \mathrm{~min}$. Cell viability was evaluated by the trypan blue exclusion test.

\section{Measurement of ROS production by luminol-amplified chemiluminescence}

Neutrophils $\left(5 \times 10^{5} / 0.5 \mathrm{~mL}\right)$ were resuspended in HBSS in the absence or presence of polyphenol extracts $(0,25,50,100,200$ and 250 $\mu \mathrm{g} / \mathrm{mL})$, in the presence of luminol $(10 \mu \mathrm{M})$, for $15 \mathrm{~min}$ at $37^{\circ} \mathrm{C}$, then
PMA (100 ng/mL) was added and chemiluminescence was evaluated with a luminometer (Auto Lumat LB953 model, EG \& G Berthold). Light emission was recorded in counted photons per minute (cpm) during $30 \mathrm{~min}$ at $37^{\circ} \mathrm{C}$. The percentage of inhibition was calculated in comparison to the control without polyphenol extract. To test the effect of polyphenol on $\mathrm{H}_{2} \mathrm{O}_{2}$, we use $0.003 \% \mathrm{H}_{2} \mathrm{O}_{2}$ mixed to $5 \mathrm{U}$ of $\mathrm{HRPO}$ in the presence of luminol $(10 \mu \mathrm{M})$ and increasing concentrations of polyphenol extract $(0,10,20,50,100 \mu \mathrm{g} / \mathrm{mL})$. Chemiluminescence was measured for $30 \mathrm{~min}$ as described above.

\section{Measurement of superoxide production by the cytochrome $\mathrm{c}$ reduction assay}

Neutrophils $\left(1 \times 10^{6}\right)$ were incubated during $10 \mathrm{~min}$ at $37^{\circ} \mathrm{C}$ with cytochrome c $(1 \mathrm{mg} / \mathrm{mL})$ and increasing concentrations polyphenol extract $(0,25,50,100,200,250 \mu \mathrm{g} / \mathrm{mL})$, prior to stimulation with $100 \mathrm{ng} / \mathrm{mL}$ PMA. Superoxide anion production was determined by measuring the ferric cytochrome $c$ reduction with a UVIKON 860 spectrophotometer at $550 \mathrm{~nm}$ during $10 \mathrm{~min}$.

Xanthine-Xanthine Oxidase (XXO)-derived superoxide production was determined in $1 \mathrm{~mL}$ PBS containing xanthine $(100 \mathrm{mM})$ and xanthine oxidase $(1 \mathrm{U})$, in the presence of cytochrome $\mathrm{c}$ and increasing concentrations of polyphenol extracts $(0,25,50,100,200$ and $250 \mu \mathrm{g} /$ $\mathrm{mL}$ ). Superoxide anion production was determined by measuring the ferric cytochrome $c$ reduction with spectrophotometer at $550 \mathrm{~nm}$ over $10 \mathrm{~min}$. Superoxide production values were calculated using the molar extinction coefficient of reduced cytochrome c $\left(2.1 \times 10^{4} \mathrm{~mol} / \mathrm{L}^{-1} \mathrm{~cm}^{-1}\right)$.

\section{Measurement of intracellular $\mathrm{H} 2 \mathrm{O} 2$ production by flow cytometry}

Intracellular $\mathrm{H}_{2} \mathrm{O}_{2}$ production was measured using a flow cytometric assay. The method is based on that when $2^{\prime}, 7^{\prime}$-dichlorofluorescin diacetate (DCFH-DA) probe diffuses across neutrophils membrane, it is hydrolyzed by intracellular esterases to DCFH which remains trapped within the cells. In presence of $\mathrm{H}_{2} \mathrm{O}_{2}$, non-fluorescent intracellular DCFH is oxidized to highly fluorescent $2^{\prime}, 7^{\prime}$-dichlorofluorescein (DCF). PMNs ( $5 \times 10^{5}$ cells) in Hank's were incubated for 15 min with 2,7-DCFH-DA $(100 \mathrm{mmol} / \mathrm{l})$ in the dark and in a water bath at $37^{\circ} \mathrm{C}$ with gentle agitation. Thereafter, polyphenol extract was added at increasing concentrations $(0,25,50,100$ and $200 \mu \mathrm{g} / \mathrm{mL})$ to the cells and further incubated for $10 \mathrm{~min}$. Neutrophils were stimulated with PMA (100 ng/mL) over $15 \mathrm{~min}$. The reaction was stopped at $4^{\circ}$ for 15 min. Flow cytometric analysis was performed with a Becton Dickinson FACSCantoII (Immuno cytometry Systems). The fluorescence intensity
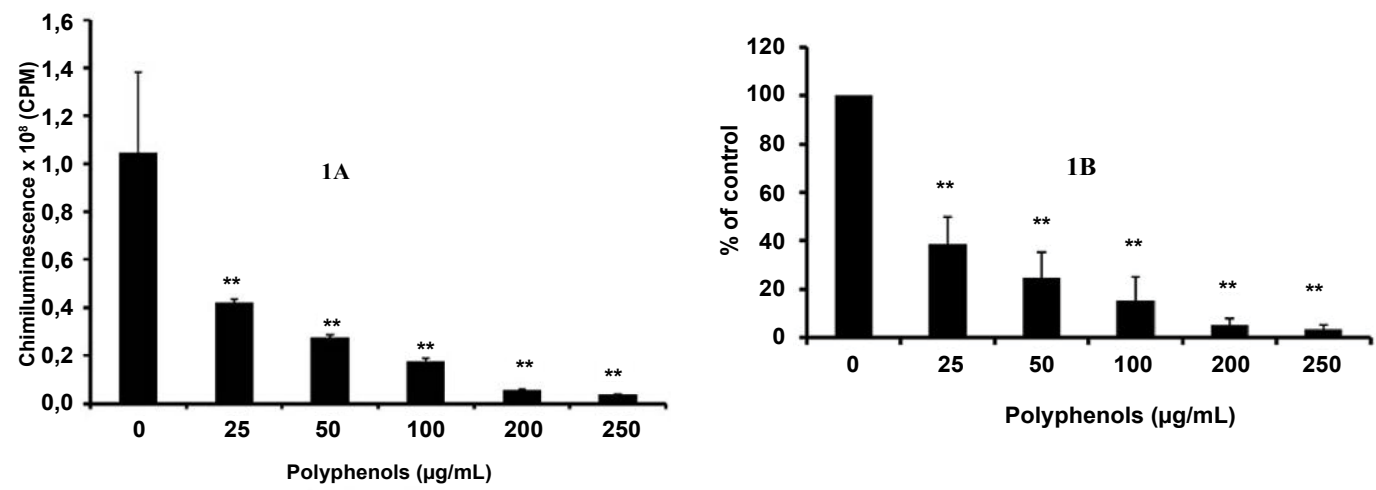

Figure 1: Effect of the polyphenols extract on ROS production by human neutrophils. Neutrophils were incubated with the OMW polyphenols extract at increasing concentrations and stimulated or not with PMA. Luminol-amplified chemiluminescence was measured during 30 min. Data are expressed as means $\pm S E M ; n=3,{ }^{*} p<0.05$. 
Citation: Bedouhene S, Hurtado-Nedelec M, Sennani N, Marie JC, Benna JE, et al. (2014) Polyphenols Extracted from Olive Mill Wastewater Exert a Strong Antioxidant Effect in Human Neutrophils. Int J Waste Resources 4: 161. doi: 10.4172/2252-5211.1000161
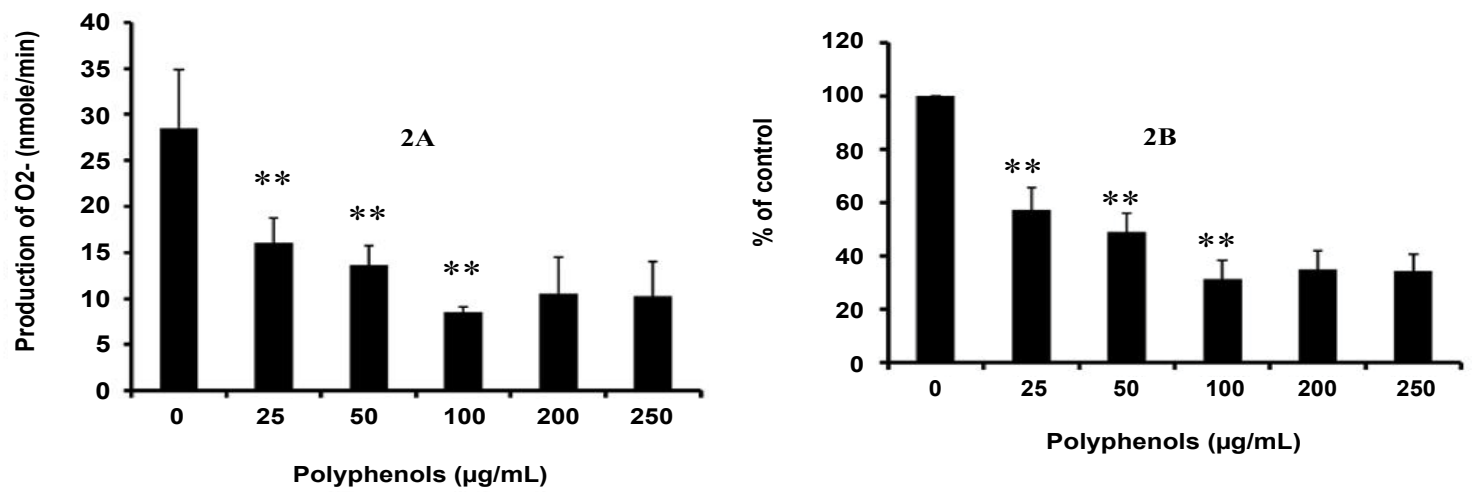

Figure 2: Effect of the polyphenols extract on superoxide anions production by human neutrophils. Neutrophils were incubated with the OMW polyphenols extract at increasing concentrations in the presence of cytochrome $c$ and stimulated or not with PMA. Production of superoxide anions was monitored at $550 \mathrm{~nm}$. Data are expressed as means $\pm \mathrm{SEM} ; \mathrm{n}=3,{ }^{*} \mathrm{p}<0.05$.
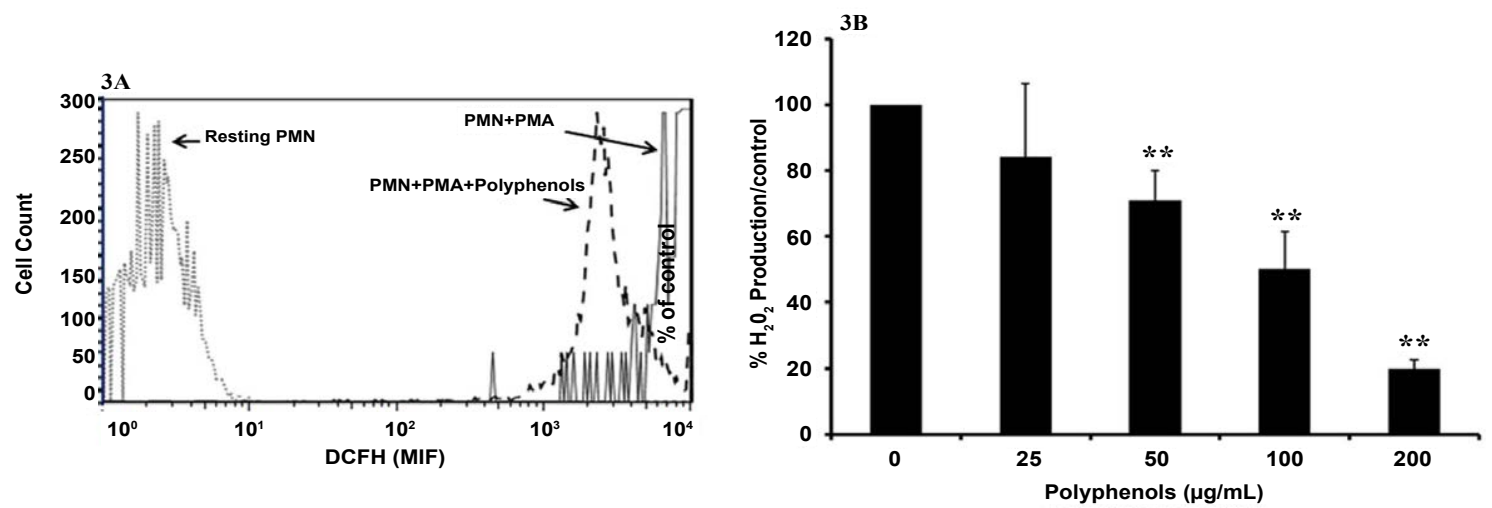

Figure 3: Effect of the polyphenols extract on DCFH-detected $\mathrm{H} 2 \mathrm{O} 2$ production. Neutrophils were incubated with DCFH-DA at $37{ }^{\circ} \mathrm{C}$ at increasing concentrations of polyphenols extract. Flow cytometric analysis was performed with a Becton Dickinson FACSCantoll. Representative FACS profile of neutrophils stimulation and the effect of polyphenols extract (Counts: number of neutrophils; MFI: Mean fluorescence intensity). The results are calculated using a stimulation index (SI), namely the ratio of MFI of stimulated cells to that of unstimulated cells. Data are expressed as means $\pm S E M, n=3 ;{ }^{*} p<0.05$.

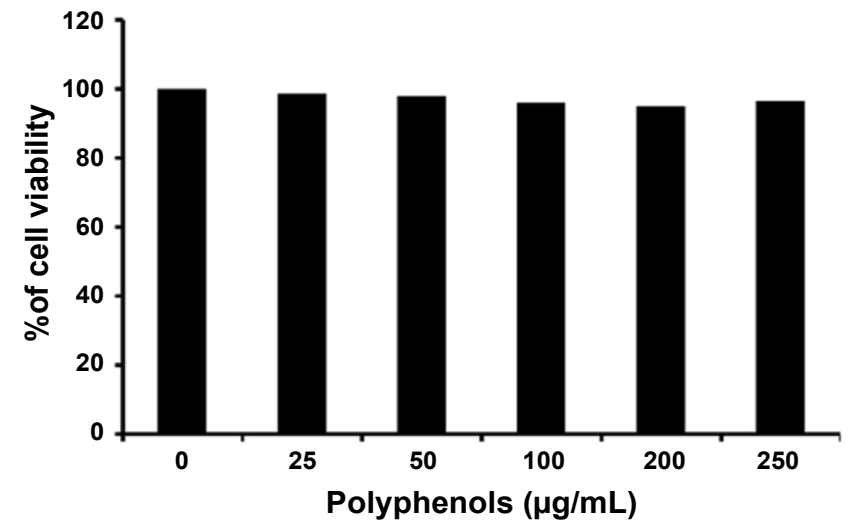

Figure 4: Effect of the polyphenols extract on neutrophil viability. Isolated human neutrophils were exposed to polyphenols extract at concentrations. Viability was evaluated with adding Trypan Blue, and blue cells were counted. \% of viable cells was expressed compared to control conditions (without polyphenols). Results are expressed as mean+/- SEM, $n=3,{ }^{*} p<0.05$.

was measured simultaneously at wavelength of $488 \mathrm{~nm}$ for excitation and at $530 \mathrm{~nm}$ for emission. The data were analyzed using FACSDiva program and results are expressed as the mean fluorescence intensity (MFI) was used to quantitate the responses. The effect of polyphenol extract on $\mathrm{H}_{2} \mathrm{O}_{2}$ production was calculated by using a stimulation index (SI), namely the ratio of the MFI of stimulated cells versus that of unstimulated cells.

\section{Statistical analysis}

The data are presented as a percentage of the control and was calculated according to the equation: [\% of control $=$ (Response with polyphenol extract/Control Response) x 100]. Statistical analysis was established between controls and samples treated with polyphenols extract using student $t$ - test.

\section{Results:}

\section{Extraction of polyphenols from olive mill wastewater}

Olive mill wastewater was collected from the region of Kabylia the most important producer of olive oil in Algeria. In this region, most of the olive trees are chemlal olive trees. Extraction of phenolic compounds was carried out on olive mill wastewater samples obtained from a continuous olive oil processing plant as described in material and method section. Total polyphenol compounds in OMW extract was determined by the Folin-Ciocalteu assay according to the method described by Singleton [26]. The content of total polyphenols is reported as gallic acid equivalents (EqGA) by reference to standard curve. After purification, we evaluated a content of polyphenol compounds in the 

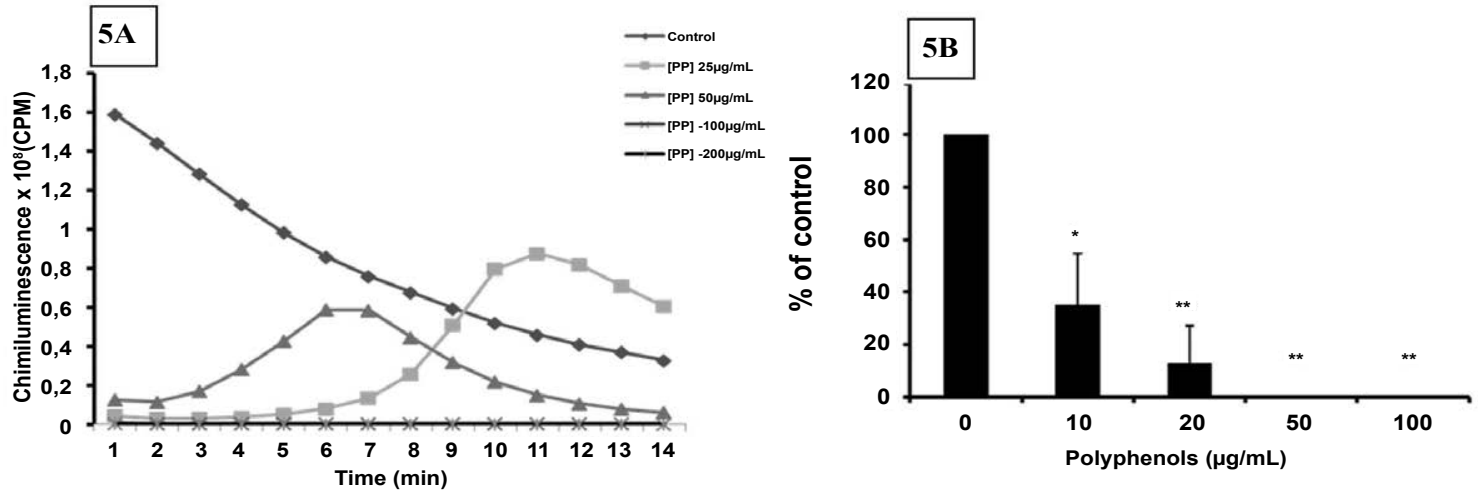

Figure 5: Effect of the polyphenols extract on luminol-amplified chemiluminescence in acellular system. $\mathrm{H} 2 \mathrm{O} 2$ and $\mathrm{HRPO}$ were incubated with polyphenols extract at increasing concentrations. Luminol-amplified chemiluminescence was measured during 30 min. Data are expressed as means $\pm \mathrm{SEM}, \mathrm{n}=3$, * $\mathrm{p}<0.05$.

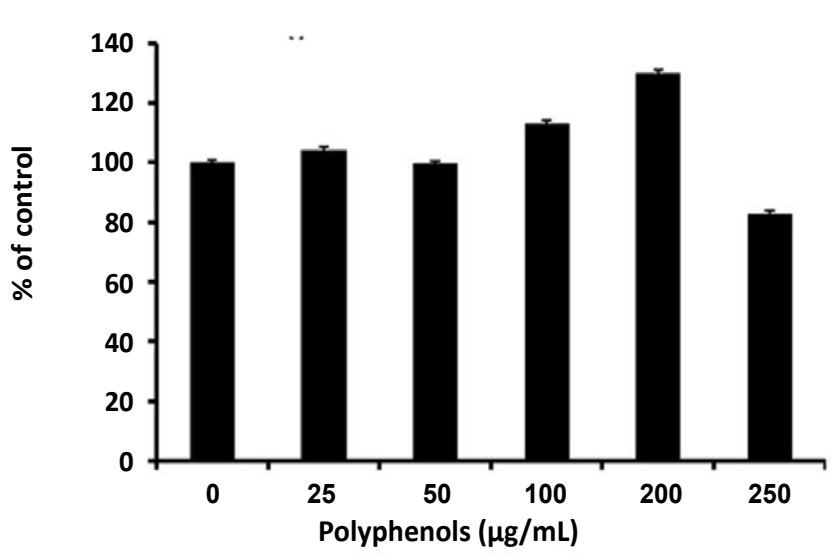

Figure 6: Effect of the polyphenols extract on superoxide anion production by the xanthine/xanthine oxidase cell free system. The polyphenols extract was incubated at increasing concentrations with xanthine oxidase, xanthine was added and superoxide was measured by the cytochrome $c$ reduction assay at $550 \mathrm{~nm}$. Results are expressed as the \% of control without the extract. Data are expressed as means \pm SEM, obtained in three independent experiments.

OMW extract by $0.148 \mathrm{mg}$ EqGA/mg extract.

\section{Effect of polyphenol extract from OMW on neutrophil ROS production}

To evaluate the effect of the polyphenol extract on human neutrophil ROS production, freshly isolated neutrophils were treated with increasing concentrations of the polyphenol extract $(0,25,50,100$, 200 and $250 \mu \mathrm{g} / \mathrm{mL}$ ), chemiluminescence was measured using luminol as probe. Luminol-amplified chemiluminescence detects multiple ROS, mainly superoxide anion, hydrogen peroxide and hypochlorous acid. The result shows that the polyphenol extract inhibited total ROS production by PMA-stimulated neutrophils (Figures $1 \mathrm{~A}$ and $1 \mathrm{~B}$ ). This result suggests that the total polyphenol extract from OMW may scavenge ROS or affect the neutrophil NADPH oxidase activity or its upstream activation.

\section{Effect of the polyphenol extract on superoxide production by neutrophils}

To assess specifically the effect of the polyphenol extract on superoxide anion production, neutrophils were pre-incubated for $10 \mathrm{~min}$ at $37^{\circ} \mathrm{C}$ with cytochrome $\mathrm{c}$ and the polyphenol extract and then were stimulated with PMA. Superoxide anion production was determined by measuring the reduction of cytochrome $\mathrm{c}$ at $550 \mathrm{~nm}$ with a UVIKON 860 spectrophotometer. The result shows that the polyphenol extract inhibited the cytochrome $\mathrm{c}$ reduction (Figures $2 \mathrm{~A}$ and $2 \mathrm{~B}$ ). This suggests that the extract may affect NADPH oxidase activity in neutrophils or could scavenge superoxide anions.

Effect of the polyphenol extract on $\mathrm{H} 2 \mathrm{O} 2$ production by neutrophils

To test the effect of increasing concentration of polyphenol extract on intracellular production of $\mathrm{H}_{2} \mathrm{O}_{2}$ by neutrophil in response to PMA, we used DCFH probe which is fluorescent in presence of $\mathrm{H}_{2} \mathrm{O}_{2} \mathrm{We}$ calculated the effect of polyphenol extract on $\mathrm{H}_{2} \mathrm{O}_{2}$ production by using a stimulation index (SI), namely the ratio of stimulated cells to that of unstimulated cells. The neutrophils were identified on the basis of forward and side scatter alone and analysed in combination with the DCFH probe. The fluorescence intensity decreased in neutrophils treated by polyphenols cells as compared to control cells, this effect was dependent on increasing concentrations of polyphenol extract. These results (Figures $3 \mathrm{~A}$ and $3 \mathrm{~B}$ ) showed that the polyphenol extract inhibited intracellular production of $\mathrm{H}_{2} \mathrm{O}_{2}$, although at higher concentrations than those which inhibited chemiluminescence and cytochrome c reduction.

\section{The polyphenol extract from OMW has no effect on human neutrophil viability}

To verify that the inhibitory effect of the polyphenol extract was not due to its toxic activity on neutrophils, we examined its effect on cell viability using trypan blue exclusion assay. The result shows that after $30 \mathrm{~min}$ of neutrophils incubation with increasing concentrations of polyphenols, cell viability was greater than $95 \%$ (Figure 4 ). Thus cell viability was not affected by polyphenol extract.

\section{Effect of polyphenol extract on $\mathrm{H} 2 \mathrm{O} 2$ and superoxide anion in cell-free systems}

To identify the specific target of polyphenols extract, pure $\mathrm{H}_{2} \mathrm{O}_{2}$ was incubated with increasing concentrations of the polyphenol extract and then the luminol-amplified chemiluminescence assay with HRPO (5U) was used to detect $\mathrm{H}_{2} \mathrm{O}_{2}$. Results show that polyphenols extract scavenges $\mathrm{H}_{2} \mathrm{O}_{2}$ at low concentrations in a dose dependent manner (Figures 5A and 5B). We also studied the effect of polyphenol extract on superoxide anion produced by the Xanthine/Xanthine Oxidase. Results show that polyphenols extract did not inhibit cytochrome $c$ reduction (Figure 6). 
Citation: Bedouhene S, Hurtado-Nedelec M, Sennani N, Marie JC, Benna JE, et al. (2014) Polyphenols Extracted from Olive Mill Wastewater Exert a Strong Antioxidant Effect in Human Neutrophils. Int J Waste Resources 4: 161. doi: 10.4172/2252-5211.1000161

\section{Discussion}

In this study, we extracted polyphenols from olive mill wastewater (OMW) from a specific variety of olive tree, the chemlal olive tree and tested its effects on ROS production by human neutrophils. Firstly, we used luminol-amplified chemiluminescence, a technique which detects the total ROS production. Results show that, in PMA stimulated neutrophils, the polyphenol extract significantly inhibits total ROS production in a dose-dependent manner. Secondly, using the cytochrome $c$ reduction assay, a specific method to measure extracellular superoxide anions $\left(\mathrm{O}_{2}{ }^{-}\right)$production, we found that the polyphenol extract significantly inhibited neutrophil's $\mathrm{O}_{2}^{--}$production. Thirdly, using flow cytometry and DCFH probe, we showed that the polyphenol extract at low concentrations significantly inhibited the intracellular production of $\mathrm{H}_{2} \mathrm{O}_{2}$, in a dose-dependent manner. These effects were not due to a toxic effect of the polyphenol extract since cell viability was not affected. Interestingly, the polyphenol extract was able to react with pure $\mathrm{H}_{2} \mathrm{O}_{2}$ in vitro but not with $\mathrm{O}_{2}^{--}$produced by the xanthine/xanthine oxidase system. These results suggest that the polyphenol extract could have a double effect, 1) scavenging $\mathrm{H}_{2} \mathrm{O}_{2}$ and 2 ) inhibiting NADPH oxidase activity or its upstream activation. To check the second possibility, we tested the effect of the polyphenol extract on isolated neutrophil membranes containing activated NADPH oxidase. We found no effect on the isolated enzyme (data not shown). These results suggest that the polyphenol extract is able to affect NADPH oxidase activation, probably by interfering with the neutrophil signaling pathways involved in NADPH oxidase activation.

Our results show that OMW from Chemlal variety is a rich source of antioxidants such as phenolic compounds. Among the polyphenol compounds present in olive mill wastewater, only hydroxytyrosol and oleuropein showed a highly antioxidant effect [27-29]. Many recent human and animal studies have shown a spectrum of highly interesting bioactivities of polyphenols from olive, including antimicrobial activity, anti-cancer activity, anti-inflammatory activity and beneficial effect in cardiovascular diseases [3,8-10,12]. Also, these effects are well sustained by epidemiological studies on Mediterranean diet [30].

It has been found that polyphenol compounds are highly absorbed by human cells [31], and stored in vivo in some tissues such as prostate and breast tissues $[30,32,33]$. These data suggest that assimilated polyphenols can protect against $\mathrm{H}_{2} \mathrm{O}_{2}$ toxicity and exert beneficial effects on health. The total polyphenol extract could have a more effective effect in vivo due to synergistic action and effects of individual compounds.

It is well established that ROS generated by neutrophils and monocytes/macrophages are involved in inflammatory diseases such as inflammatory bowel diseases, cardiovascular diseases and rheumatoid arthritis [34].The polyphenol extract could be beneficial in these diseases due to its inhibitory action on neutrophil ROS production and also by scavenging extracellular $\mathrm{H}_{2} \mathrm{O}_{2}$ which is the most diffusible ROS. Thus the polyphenol can protect tissues of different organs from $\mathrm{H}_{2} \mathrm{O}_{2}$, limiting its bystander toxic effects. The scavenging of $\mathrm{H}_{2} \mathrm{O}_{2}$ polyphenols has also been reported in vitro by Ju et al. [35] and in neutrophils with another extract by Paula et al [36].

In conclusion, the polyphenol extract from OMW is a powerful hydrogen peroxide scavenger and a powerful inhibitor of neutrophil NADPH oxidase activation. These compounds present in OMW could contribute to the prevention of diseases in which ROS are involved. OMW could also be used as immunomodulatory compounds and a therapeutic adjuvant in the treatment of neutrophil-mediated inflammatory diseases as an alternative to synthetic antioxidants in pharmaceutical and agroalimentary process. As OMW is a significant source of phenolic compounds beneficial for health, its utilization as a resource of polyphenols can be valorized to reduce environmental waste [37]. Thus, the extraction of polyphenol compounds from OMW is a fundamental step before any biological degradation of this waste. OMW could be used as a source of antioxidant compounds with a clear impact on both health and environment.

\section{References}

1. Nafzaoui A (1991) Valorization des sous-produits de l'olivier. Options méditerranéennes, série séminaires $16: 101-108$.

2. Kapellakis IE, Tsagarakis KP, Avramaki C, Angelakis AN (2006): Olive mil wastewater management in river basins: A case in Greece. Agricultuural Water management 82: 354-370.

3. Czerwinska M, Kiss AK, Naruszewicz M (2012) A comparative study of the effects of oleuropein and oleacein on human neutrophil oxidative bursts and monocytes nitric oxide production. Food Chemistry 131: 940-947.

4. De Marco E, Sa Varese M, Paduano A, Sacchi R (2007) Characterization and fractionnement of phenolic compounds extracted from olive mill wastewaters. Food Chemistry 104: 858-867.

5. Chimi HJ, Cillard $P$ and Rahmani M (1991) Peroxyl and hydroxyl radica scavenging activity of some natural phenolic antioxidants. JAOCS 68: 307-312.

6. Babich H, Visioli $F(2003)$ In vitro cytotoxicity to human cells in culture of some phenolics from olive oil. Farmaco 58: 403-407.

7. Kastorini CM, Milionis HJ, Goudevenos JA, Panagiotakos DB (2010) Mediterranean diet and coronary heart disease: is obesity a link? - A systematic review. Nutr Metab Cardiovasc Dis 20: 536-551.

8. Ozsoy N, Candoken E and Akev N (2009) Implications for degenerative disorders: Antioxidative activity, total phenols, flavonoids, ascorbic acid ß-carotene anda -tocopherol in Aloe vera. Oxidative Medicine and Cellular Longevity (Landes Bioscience) 2: 99-106.

9. Isik S, Karagöz A, Karaman S, Nergiz C (2012) Proliferative and apoptotic effects of olive extracts on cell lines and healthy human cells. Food Chemistry 134: $29-36$

10. Yang CS, Wang H, Li GX, Yang Z, Guan F, et al. (2011) Cancer prevention by tea: Evidence from laboratory studies. Pharmacol Res 64: 113-122.

11. de la Puerta R, Martínez-Domínguez E, Ruíz-Gutiérrez V (2000) Effect of minor components of virgin olive oil on topical antiinflammatory assays. Z Naturforsch C 55: 814-819.

12. Impellizzeri D, Esposito E, Mazzon E, Paterniti I, Di Paola R, et al. (2011) The effects of oleuropein aglycone, an olive oil compound, in a mouse model of carrageenan-induced pleurisy. Clin Nutr 30: 533-540.

13. Miles EA, Zoubouli P, Calder PC (2005) Differential anti-inflammatory effects of phenolic compounds from extra virgin olive oil identified in human whole blood cultures. Nutrition 21: 389-394.

14. Covas MI, Nyyssönen K, Poulsen HE, Kaikkonen J, Zunft HJ, et al. (2006) The effect of polyphenols in olive oil on heart disease risk factors: a randomized trial. Ann Intern Med 145: 333-341.

15. Bisignano G, Tomaino A, Lo Cascio R, Crisafi G, Uccella N, et al. (1999) On the in-vitro antimicrobial activity of oleuropein and hydroxytyrosol. J Pharm Pharmacol 51: 971-974.

16. Capasso R, Evidente A, Schivo L, Orru G, Marcialis MA, et al. (1995) Antibacterial polyphenols from olive oil mill waste waters. J Appl Bacteriol 79 : 393-398.

17. Rodriguez-Vaquero MJ, Alberto MR, Manca-de-Nadra MC (2007) Antibacterial effect of phenolic compounds from different wines. Food Control 18: 93-101.

18. Yamada K, Ogawa H, Hara A, Yoshida Y, Yonezawa Y, et al. (2009) Mechanism of the antiviral effect of hydroxytyrosol on influenza virus appears to involve morphological change of the virus. Antiviral Res 83: 35-44.

19. Favier A (2006) Le stress oxydant, Intérêt conceptuel et expérimental dans la compréhension des mécanismes des maladies et potentiel thérapeutique. L'actualité chimique 11-12: 108-115 
Citation: Bedouhene S, Hurtado-Nedelec M, Sennani N, Marie JC, Benna JE, et al. (2014) Polyphenols Extracted from Olive Mill Wastewater Exert a Strong Antioxidant Effect in Human Neutrophils. Int J Waste Resources 4: 161. doi: 10.4172/2252-5211.1000161

Page 6 of 6

20. Gougerot-Pocidalo MA, Elbim C, Dang PM, El Benna J (2006) [Primary immune deficiencies in neutrophil functioning]. Presse Med 35: 871-878.

21. Rotondo S, Rajtar G, Manarini S, Celardo A, Rotillo D, et al. (1998) Effect of transresveratrol, a natural polyphenolic compound, on human polymorphonuclear leukocyte function. Br J Pharmacol 123: 1691-1699.

22. Alvarado C, Alvarez $P$, Jiménez L, De la Fuente M (2005) Improvement of leukocyte functions in young prematurely aging mice after a 5 -week ingestion of a diet supplemented with biscuits enriched in antioxidants. Antioxid Redox Signal 7: 1203-1210.

23. Léger CL1, Kadiri-Hassani N, Descomps B (2000) Decreased superoxide anion production in cultured human promonocyte cells (THP-1) due to polyphenol mixtures from olive oil processing wastewaters. J Agric Food Chem 48: 5061-5067.

24. Schaffer S, Müller WE, Eckert GP (2010) Cytoprotective effects of olive mill wastewater extract and its main constituent hydroxytyrosol in PC12 cells. Pharmacol Res 62: 322-327.

25. Visioli F, Bellomo G, Galli C (1998) Free radical-scavenging properties of olive oil polyphenols. Biochem Biophys Res Commun 247: 60-64.

26. Singleton VL, Rossi JA (1965) Colorimetry of total phenolics with phosphomolybdic-phosphotungstic reagents. Am J Enol Vitic; 16: 144-158.

27. O'Dowd Y, Driss F, Dang PM, Elbim C, Gougerot-Pocidalo MA, et al. (2004) Antioxidant effect of hydroxytyrosol, a polyphenol from olive oil: scavenging of hydrogen peroxide but not superoxide anion produced by human neutrophils. Biochem Pharmacol 68: 2003-2008

28. Ju HY, Chen SC, Wua KJ, Kuo HC, Hseu YC, et al. (2012) Antioxidant phenolic profile from ethyl acetate fraction of Fructus Ligustri Lucidi with protection against hydrogen peroxide-induced oxidative damage in SH-SY5Y cells. Food Chem Toxicol 50: 492-502.
29. Paula FS, Kabeya LM, Kanashiro A, de Figueiredo AS, Azzolini AE, et al (2009) Modulation of human neutrophil oxidative metabolism and degranulation by extract of Tamarindus indica L. fruit pulp. Food Chem Toxicol 47: 163-170.

30. Parzonko A, Naruszewicz M (2010) Silymarin inhibits endothelial progenitor cells' senescence and protects against the antiproliferative activity of rapamycin: preliminary study. J Cardiovasc Pharmacol 56: 610-618.

31. Visioli F, Poli A, Gall C (2002) Antioxidant and other biological activities of phenols from olives and olive oil. Med Res Rev 22: 65-75.

32. Shivashankara KS and Acharya SN (2010) Uptake of Polyphenols in Tissues. Bioavailability of Dietary Polyphenols and the Cardiovascular Diseases. The Open Nutraceuticals Journal 3: 227-241.

33. Scalbert A, Williamson G (2000) Dietary intake and bioavailability of polyphenols. J Nutr 130: 2073S-85S.

34. Manach C, Williamson G, Morand C, Scalbert A, Rémésy C (2005) Bioavailability and bioefficacy of polyphenols in humans. I. Review of 97 bioavailability studies. Am J Clin Nutr 81: 230S-242S.

35. Moreira MR, Kanashiro A, Kabeya LM, Polizello ACM, Azzolini AECS, et al. (2007) Neutrophil effector functions triggered by Fc-gamma and/or complement receptors are dependent on B-ring hydroxylation pattern and physicochemical properties of flavonols. Life Sci 81: 317-326.

36. Conner EM, Grisham MB (1996) Inflammation, free radicals, and antioxidants Nutrition 12: 274-277.

37. Kalogerakis N, Politi M, Foteinis S, Chatzisymeon E, Mantzavinos D (2013) Recovery of antioxidants from olive mill wastewaters: a viable solution that promotes their overall sustainable management. J Environ Manage 128: 749-758. 